\title{
Insulin resistance contributes to racial disparities in breast cancer prognosis in US women
}

Emily J. Gallagher ${ }^{1,2,3^{*}}$, Kezhen Fei ${ }^{4,5}$, Sheldon M. Feldman ${ }^{6}$, Elisa Port ${ }^{7}$, Neil B. Friedman ${ }^{8}$, Susan K. Boolbol' ${ }^{9}$, Brigid Killelea ${ }^{10}$, Melissa Pilewskie ${ }^{11}$, Lydia Choi ${ }^{12}$, Tari King ${ }^{11}$, Anupma Nayak ${ }^{13}$, Rebeca Franco ${ }^{4,5}$, Daliz Cruz ${ }^{4,5}$, Irini M. Antoniou', Derek LeRoith ${ }^{1,2,3+}$ and Nina A. Bickell ${ }^{2,3,4,5+}$

\begin{abstract}
Background: Racial disparities in breast cancer survival between Black and White women persist across all stages of breast cancer. The metabolic syndrome (MetS) of insulin resistance disproportionately affects more Black than White women. It has not been discerned if insulin resistance mediates the link between race and poor prognosis in breast cancer. We aimed to determine whether insulin resistance mediates in part the association between race and breast cancer prognosis, and if insulin receptor (IR) and insulin-like growth factor receptor (IGF-1R) expression differs between tumors from Black and White women.

Methods: We conducted a cross-sectional, multi-center study across ten hospitals. Self-identified Black women and White women with newly diagnosed invasive breast cancer were recruited. The primary outcome was to determine if insulin resistance, which was calculated using the homeostatic model assessment of insulin resistance (HOMA-IR), mediated the effect of race on prognosis using the multivariate linear mediation model. Demographic data, anthropometric measurements, and fasting blood were collected. Poor prognosis was defined as a Nottingham Prognostic Index (NPI) > 4.4. Breast cancer pathology specimens were evaluated for IR and IGF-1R expression by immunohistochemistry $(\mathrm{IHC})$.

Results: Five hundred fifteen women were recruited (83\% White, 17\% Black). The MetS was more prevalent in Black women than in White women (40\% vs 20\%, $p<0.0001)$. HOMA-IR was higher in Black women than in White women $(1.9 \pm 1.2$ vs $1.3 \pm 1.4, p=0.0005$ ). Poor breast cancer prognosis was more prevalent in Black women than in White women (28\% vs $15 \%$. $p=0.004)$. HOMA-IR was positively associated with NPI score $(r=0.1, p=0.02)$. The mediation model, adjusted for age, revealed that HOMA-IR significantly mediated the association between Black race and poor prognosis $(\beta=0.04,95 \% \mathrm{Cl}$ $0.005-0.009, p=0.002$ ). IR expression was higher in tumors from Black women than in those from White women (79\% vs $52 \%, p=0.004)$, and greater IR/IGF-1R ratio was also associated with higher NPI score (IR/GF-1R $>1: 4.2 \pm 0.8$ vs IR/IGF-1R= $1: 3.9 \pm 0.8$ vs IR/IGF-1R $<1: 3.5 \pm 1.0, p<0.0001)$.

(Continued on next page)
\end{abstract}

\footnotetext{
* Correspondence: Emily.gallagher@mssm.edu

${ }^{\dagger}$ Derek LeRoith and Nina A. Bickell are co-senior authors on this manuscript.

'Division of Endocrinology, Diabetes and Bone Disease, Icahn School of

Medicine at Mount Sinai, 1428 Madison Avenue, Box 1055, New York, NY 10029, USA

${ }^{2}$ Department of Medicine, Icahn School of Medicine at Mount Sinai, New York, NY, USA

Full list of author information is available at the end of the article
}

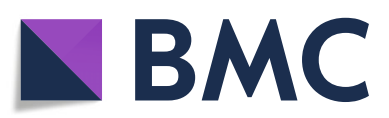

(c) The Author(s). 2020 Open Access This article is licensed under a Creative Commons Attribution 4.0 International License, which permits use, sharing, adaptation, distribution and reproduction in any medium or format, as long as you give appropriate credit to the original author(s) and the source, provide a link to the Creative Commons licence, and indicate if changes were made. The images or other third party material in this article are included in the article's Creative Commons licence, unless indicated otherwise in a credit line to the material. If material is not included in the article's Creative Commons licence and your intended use is not permitted by statutory regulation or exceeds the permitted use, you will need to obtain permission directly from the copyright holder. To view a copy of this licence, visit http://creativecommons.org/licenses/by/4.0/ The Creative Commons Public Domain Dedication waiver (http://creativecommons.org/publicdomain/zero/1.0/) applies to the data made available in this article, unless otherwise stated in a credit line to the data. 
(Continued from previous page)

Conclusions: In this multi-center, cross-sectional study of US women with newly diagnosed invasive breast cancer, insulin resistance is one factor mediating part of the association between race and poor prognosis in breast cancer.

Keywords: Breast cancer, Cross-sectional study, Prognosis, Disparities, Insulin resistance, Insulin receptor, Insulin-like growth factor receptor

\section{Introduction}

The metabolic syndrome is a set of biological factors (abdominal obesity, hypertension, dyslipidemia, and dysglycemia), associated with an increased risk of a number of diseases including cancer $[1,2]$. In breast cancer, the metabolic syndrome has been associated with an increased risk of developing cancer, and a worse prognosis $[3,4]$. In the 2007-2012 US National Health and Nutrition Examination Survey (NHANES), the overall prevalence of the metabolic syndrome was 34\% [5]. Non-Hispanic Black women were found to be $20 \%$ more likely to have the metabolic syndrome than nonHispanic White women [5].

Non-Hispanic Black women still experience 39\% higher rates of breast cancer mortality than nonHispanic White women, despite similar incidence [6]. Black women have higher rates of triple-negative breast cancer (TNBC) [7-10] and also experience higher mortality from estrogen receptor (ER)-positive breast cancers [11]. A number of complex factors have been proposed to contribute to the disparities in breast cancer mortality including access to care, screening, and treatment; socioeconomic factors; systemic metabolic conditions; tumor biology; and epigenetic and genetic factors [12, 13].

Insulin resistance and endogenous hyperinsulinemia are key features that underlie the development of the metabolic syndrome [14]. Studies have reported that women with early-stage breast cancer and endogenous hyperinsulinemia have decreased rates of recurrence-free survival [9]. Preclinical studies have found that hyperinsulinemia promotes the growth and metastasis of breast cancers by activating the insulin receptor (IR)/insulinlike growth factor 1 receptor (IGF-1R) signaling pathways $[15,16]$. Differences in hepatic insulin metabolism have been reported between African American and European American women, leading to higher circulating insulin levels in African American women [17]. Whether hyperinsulinemia and tumor IR expression contribute to the racial disparities in breast cancer prognosis has not previously been explored.

In this study, we aimed to determine whether insulin resistance (determined by the homeostatic model assessment of insulin resistance, HOMA-IR) mediates the association between race and breast cancer prognosis, which was determined by the Nottingham Prognostic Index (NPI). We additionally explored whether expression of the IR and IGF-1R in the breast cancer cells was associated with race and worse breast cancer prognosis.

\section{Methods \\ Patient accrual, data collection, and laboratory measurements}

In this cross-sectional study, women were recruited shortly after the diagnosis of a new primary invasive breast cancer from ten US hospital sites, including five academic medical centers and five community hospitals in five states: New York, New Jersey, Connecticut, Maryland, and Michigan. A survey assessing breast cancer and metabolic syndrome risk factors, anthropometric measures, fasting blood, and tissue samples was collected. Institutional Review Board (IRB) approval was obtained from all participating sites. Recruitment began in March 2013. Women who were eligible for the study were aged 21 years or more and self-identified as being Black women (including Hispanic Black women) or White women (excluding Hispanic White women). Exclusion criteria included women with type 1 or type 2 diabetes being treated with oral or injectable medication; previous bariatric surgery; glucocorticoid treatment within 2 weeks of recruitment for blood testing, biopsy, or surgical resection; end-stage renal disease or hepatic cirrhosis; prior organ transplantation; and receipt of neoadjuvant chemo- or hormonal therapy for breast cancer prior to blood tests or tissue sampling. We excluded women with type 2 diabetes on oral or injectable medications in order to evaluate HOMA-IR in the absence of medication that could affect insulin sensitivity, secretion, or measurement of endogenous insulin levels; however, it led to a lower rate of eligible Black women who had higher rates of type 2 diabetes.

Clinical data recorded included self-reported smoking, alcohol intake, diet, physical activity, education, income, and health insurance. Breast cancer screening history was also recorded and was defined as inadequate if women between the ages of 50-74 years had not had a mammogram in the 2 years prior to the mammogram that led to the current diagnosis of breast cancer. Charlson Comorbidity Index was calculated [18].

At the study visit, each participant had height (m) and weight $(\mathrm{kg})$ measurements recorded from which body 
mass index (BMI) was calculated $\left(\mathrm{kg} / \mathrm{m}^{2}\right)$. Waist circumference $(\mathrm{cm})$ was measured using the NHANES procedures [19]. Blood pressure was obtained using a clinical electronic blood pressure monitor. Venous blood was drawn after an overnight fast (minimum $8 \mathrm{~h}$ ) for plasma glucose, serum insulin, C-peptide, and a lipid panel [total cholesterol, high-density lipoprotein (HDL) cholesterol, low-density lipoprotein (LDL) cholesterol, and triglycerides (TG)]. Insulin resistance was calculated by the HOMA-IR equation: [fasting glucose $(\mathrm{mg} / \mathrm{dL}) \times$ fasting serum insulin $(\mu \mathrm{U} / \mathrm{mL})] / 405$.

\section{Definitions of obesity, metabolic syndrome, and insulin resistance}

Obesity was defined as a BMI of $\geq 30 \mathrm{~kg} / \mathrm{m}^{2}$, or by the Adult Treatment Panel (ATP) III waist circumference (WC) cutoff of $\geq 88 \mathrm{~cm}$. The metabolic syndrome was defined as having three or more of the following five criteria: (1) WC $\geq 88 \mathrm{~cm}$; (2) triglycerides $\geq 150 \mathrm{mg} / \mathrm{dL}$, or on treatment for hypertriglyceridemia; (3) $\mathrm{HDL}<50 \mathrm{mg} /$ $\mathrm{dL}$; (4) fasting glucose $\geq 100 \mathrm{mg} / \mathrm{dL}$; (5) systolic blood pressure $\geq 130 \mathrm{mmHg}$ or diastolic blood pressure $\geq 85$ $\mathrm{mmHg}$, or on treatment for hypertension [20]. Insulin resistance was defined as a HOMA-IR score of $>2.8$, the upper quartile of the US population, reported by NHANES III [21].

\section{Breast cancer subtype, stage, and prognosis determination}

Clinical pathology reports were obtained from the patients' electronic medical records to classify breast cancers as ER positive, HER2 overexpressing, or TNBC. The Nottingham Prognostic Index (NPI) score was calculated as $0.2 \times$ tumor size $(\mathrm{cm})+$ lymph node $(\mathrm{LN})$ stage $(1$ : LN negative, $2: 1-3$ positive LNs, $3: \geq 4$ positive LNs) + histological grade (1, well-differentiated; 2 , moderately differentiated; 3 , poorly differentiated) [22]. Improved NPI (iNPI) was defined as previously described, adding one point for HER2 positivity, and subtracting one point for progesterone receptor (PR) positivity [23]. Tumor grade was defined by the Nottingham combined histological grade (NCHG), as recommended by the American Joint Committee on Cancer (AJCC) criteria [24]. Poor prognosis was defined as an NPI score of $>4.4$, or an iNPI $>5.4[25,26]$.

\section{Immunohistochemistry staining and analysis}

The IR and IGF-1R expression was evaluated by immunohistochemistry (IHC) in compliance with the REMARK guidelines [27]. IHC methods with antibody sources and concentrations are detailed in Supplementary file 1 . The Allred scoring system was used to assess the intensity of cell staining, and the proportion of tumor stained positive for IR and IGF-
$1 \mathrm{R}$ [28], as previously described [29, 30]. As no standard cutoffs have been determined for IR and IGF-1R staining, 0-4 was considered "low" and $>5$ was considered "high." For the IR/IGF-1R ratio, we assigned a score of $>1$ if the level of IR expression was greater than IGF-1R, 1 if IR was equal to IGF-1R expression, and $<1$ if IGF-1R was greater than IR expression.

\section{Statistical analysis}

Basic statistics were used to describe patient characteristics. Means and standard deviations were presented for continuous variables, and frequencies and proportions were presented for categorical variables. Group comparisons used $t$ tests on continuous, and $x^{2}$ tests on categorical variables. The sample size was determined based on estimated rates of insulin resistance in White women (20\%) and Black women (33\%) and a main effect OR $>1.5$ between insulin resistance and poor prognosis breast cancer between Black women and White women. We used Andrew Hay's INDIRECT macro to estimate the path coefficients in an adjusted mediator model and used bootstrapping to estimate confidence intervals for indirect effects of race on prognosis through HOMA-IR. It allowed for adjustment for the potential influence of covariates not proposed as being mediators in the model. SAS 9.4 software (SAS Institute, Cary, NC) was used for all statistical analyses. All tests were two-sided and statistical significance was set at 0.05 level.

\section{Results}

\section{Patient characteristics}

Five hundred fifteen women with newly diagnosed breast cancer were consented for inclusion in the study. Patient characteristics are shown in Table 1. Eighty-three percent $(n=428)$ self-identified as nonHispanic White women, and $17 \% \quad(n=87)$ selfidentified as Black women. There was no difference in age at breast cancer diagnosis between Black and White women. More White women (48\%) than Black women $(36 \%)$ were current smokers $(p=0.04)$. Additionally, more White women (29\%) consumed more than 2 alcoholic drinks per week than Black women (5\%), $p<0.0001$. There was no difference in the percent of Black women and White women with commercial health insurance. More Black women (75\%) than White women (31\%) had an annual income of $<\$ 75,000 \quad(p<0.0001)$ and had less than a college education $(p<0.0001)$. Sixty-eight percent of Black women had a Charlson Comorbidity Index of 1 or more, compared with $53 \%$ of White women ( $p=$ $0.01)$.

Obesity was more prevalent in Black women than in White women, whether defined by BMI ( $47 \%$ vs $19 \%$, 
Table 1 Patient and tumor characteristics by self-identified race

\begin{tabular}{|c|c|c|c|c|}
\hline & Total & White & Black & $p$ value \\
\hline$N(\%)$ & $515(100 \%)$ & $428(83 \%)$ & $87(17 \%)$ & \\
\hline Age, mean (SD) & $58.3(12.4)$ & $58.3(12.3)$ & $58.1(13.2)$ & 0.9 \\
\hline \multicolumn{5}{|l|}{ Metabolic characteristics } \\
\hline BMl, mean $\left(\mathrm{kg} / \mathrm{m}^{2}\right)$ & $27.1(6.4)$ & $26.3(5.9)$ & $31.2(6.8)$ & $<.0001$ \\
\hline Obese $\left(\mathrm{BMI} \geq 30 \mathrm{~kg} / \mathrm{m}^{2}\right)$ & $120(24 \%)$ & 79 (19\%) & $41(47 \%)$ & $<.0001$ \\
\hline Abdominal obesity $(\mathrm{WC}>88 \mathrm{~cm})$ & $332(72 \%)$ & $250(67 \%)$ & $82(96 \%)$ & $<.0001$ \\
\hline Metabolic syndrome & $120(23 \%)$ & $85(20 \%)$ & $35(40 \%)$ & $<.0001$ \\
\hline \multicolumn{5}{|l|}{ Comorbidities } \\
\hline Charlson Comorbidity Index $(\geq 1)$ & $284(55 \%)$ & $225(53 \%)$ & $59(68 \%)$ & 0.01 \\
\hline \multicolumn{5}{|l|}{ Tumor characteristics } \\
\hline Tumor size, cm & $1.5(1.2)$ & $1.5(1.2)$ & $1.7(1.2)$ & 0.2 \\
\hline Stage & & & & 0.05 \\
\hline I & $327(64 \%)$ & $281(66 \%)$ & $46(53 \%)$ & \\
\hline$\|$ & $169(33 \%)$ & $133(31 \%)$ & $36(41 \%)$ & \\
\hline III & $19(4 \%)$ & $14(3 \%)$ & $5(6 \%)$ & \\
\hline Insulin resistant (HOMA-IR > 2.8) & $57(11 \%)$ & $42(10 \%)$ & $15(17 \%)$ & 0.04 \\
\hline $\mathrm{NPI}>4.4$ & $87(17 \%)$ & $63(15 \%)$ & $24(28 \%)$ & 0.004 \\
\hline iNPI $>5.4$ & $17(3 \%)$ & $9(2 \%)$ & $8(9 \%)$ & 0.001 \\
\hline \multicolumn{5}{|l|}{ Tumor hormone receptor status } \\
\hline Estrogen receptor positive & $433(88 \%)$ & 371 (91\%) & $62(77 \%)$ & 0.0003 \\
\hline Progesterone receptor positive & 405 (83\%) & $346(85 \%)$ & $59(73 \%)$ & 0.01 \\
\hline Her2 positive & $31(6 \%)$ & $25(6 \%)$ & $6(8 \%)$ & 0.65 \\
\hline Triple negative & $38(8 \%)$ & $28(6 \%)$ & $13(16 \%)$ & 0.01 \\
\hline \multicolumn{5}{|l|}{ Screening behavior } \\
\hline Mammogram $\geq 2$ years before diagnosis & $108(22 \%)$ & $91(22 \%)$ & $17(20 \%)$ & 0.6 \\
\hline \multicolumn{5}{|l|}{ Lifestyle factors } \\
\hline Smoking: never smoker & 265 (54\%) & $211(52 \%)$ & $54(64 \%)$ & 0.04 \\
\hline Alcohol: > 2 drinks/week & $122(25 \%)$ & $118(29 \%)$ & $4(5 \%)$ & $<.0001$ \\
\hline Diet: very good/excellent diet & $264(54 \%)$ & $239(59 \%)$ & $25(30 \%)$ & $<.0001$ \\
\hline Physical activity: sedentary & $236(49 \%)$ & $184(47 \%)$ & $52(60 \%)$ & 0.02 \\
\hline \multicolumn{5}{|l|}{ Socioeconomic factors } \\
\hline Education: < college education & $85(18 \%)$ & $54(14 \%)$ & $31(38 \%)$ & $<.0001$ \\
\hline Income: $<\$ 75,000 /$ year & $70(40 \%)$ & $43(31 \%)$ & $27(75 \%)$ & $<.0001$ \\
\hline Insurance: commercial insurance & 436 (89\%) & 364 (90\%) & $72(84 \%)$ & 0.1 \\
\hline
\end{tabular}

$p<0.0001)$ or as waist circumference $(96 \%$ vs $67 \%, p<$ $0.0001)$. The metabolic syndrome was also more prevalent in Black women than in White women $(40 \%$ vs $20 \%$, $p<0.0001)$. HOMA-IR was higher in Black women $(1.9 \pm 1.2)$ than in White women $(1.3 \pm 1.4), p=0.0005$. Seventeen percent of Black women had HOMA-IR $>2.8$, compared with $9 \%$ of White women $(p=0.03)$. More White women than Black women reported that their diet was "very good/excellent" ( $59 \%$ vs $30 \%, p<0.0001$ ), and engaged in moderate or more physical activity (53\% vs $40 \%, p=0.02$ ).
Breast cancer screening and tumor characteristics

There was no difference in the rate of breast cancer screening or the AJCC stage at diagnosis between Black women and White women. However, 28\% of Black women had an NPI of $>4.4$, compared with $15 \%$ of White women $(p=0.004)$. Rates of ER-positive breast cancer were higher in White women than in Black women $(91 \%$ vs $77 \%, p=0.0003)$. There were no differences in the percent of women with HER2-positive breast cancer. TNBC was more common in Black women than in White women ( $16 \%$ vs $6 \%, p=0.01)$. 


\section{Association between insulin resistance and breast cancer prognosis}

Insulin resistance (HOMA-IR) was positively associated with NPI scores $(r=0.1 ; p=0.02)$. Poor prognosis was associated with younger age $(55.3 \pm 12.7$ vs $58.9 \pm 12.3$ years; $p=0.01$ ), and a diet that was not "very good/excellent" (58\% vs $44 \%, p=0.02$ ), but was not associated with metabolic syndrome, smoking, drinking, or exercise. To evaluate whether HOMA-IR mediated the effect of race on NPI, the multivariate linear mediation model was used, adjusting for age. The total relationship between being a Black woman and having a worse NPI was 0.54 , $p<0.0001$; the direct effect of being a Black woman to NPI was $0.50, p<0.0001$; and the direct effect of HOMA-IR on NPI was $0.067, p=0.04$, The indirect effect of race on NPI through HOMA-IR was 0.04 ( $p=$ 0.002 ) adjusting for age (Fig. 1). This model indicates that insulin resistance (measured by HOMA-IR) significantly mediated the association between race and poor prognosis, measured by NPI score.

\section{Breast cancer insulin receptor and insulin-like growth factor receptor expression}

IR and IGF-1R IHC staining was performed on 196 available tumor specimens (Table 2). Of them, 34 tumor specimens were from Black women (17\%) and 162 (83\%) were from White women. One hundred sixty-eight were ER positive, $12(6.2 \%)$ were HER2 positive by IHC, and 11 (5.7\%) were TNBCs. One hundred twenty-eight (65\%) specimens had high IGF-1R expression, and 68 (35\%) had low IGF-1R expression. One hundred twelve (57\%) of tumors exhibited high IR expression, and 84 (43\%) specimens had low expression (representative images Fig. 2). More ER-positive than ER-negative tumors had high IGF-1R expression ( $71 \%$ vs $35 \%, p=0.0006)$. These findings were consistent with previously published studies examining IGF1R RNA and protein expression in breast cancer subtypes [31-33]. No differences in IR expression were seen based on ER. TNBC exhibited no difference in intensity of IGF-1R (67\% vs $45 \%, p=0.2)$ or IR staining $(73 \%$ vs $57 \%, p=0.4)$ compared with other breast cancer subtypes, although there were only 11 cases of TNBC in the group.

There was no difference in high expression of IGF-1R by race (Black women $59 \%$ vs White women $67 \%, p=$ 0.38 ), but more Black women than White women had tumors with high IR expression (79\% vs 52\%, $p=0.004)$. Tumors with high IGF-1R expression had significantly better prognosis compared with tumors with low IGF$1 \mathrm{R}$ expression, as indicated by lower NPI scores (3.6 vs $4.1, p=0.0002)$ and iNPI (2.9 vs 3.6, $p<0.0001)$. There was no difference in prognostic scores between IR expression categories. Women with tumors that had high IR expression had larger waist circumference than women that had tumors with low IR expression (100.4 \pm 14.7 vs $93.1 \pm 15.2, p=0.002$ ).

Previous studies have reported that the ratio of IR/ IGF-1R expression is important in determining the sensitivity of the cancer cells to the effects of insulin [34]. We found that more Black women than White women had an IR/IGF-1R ratio $>1$. Additionally, an IR/IGF-1R ratio of $>1$ was associated with highest NPI (4.3) and

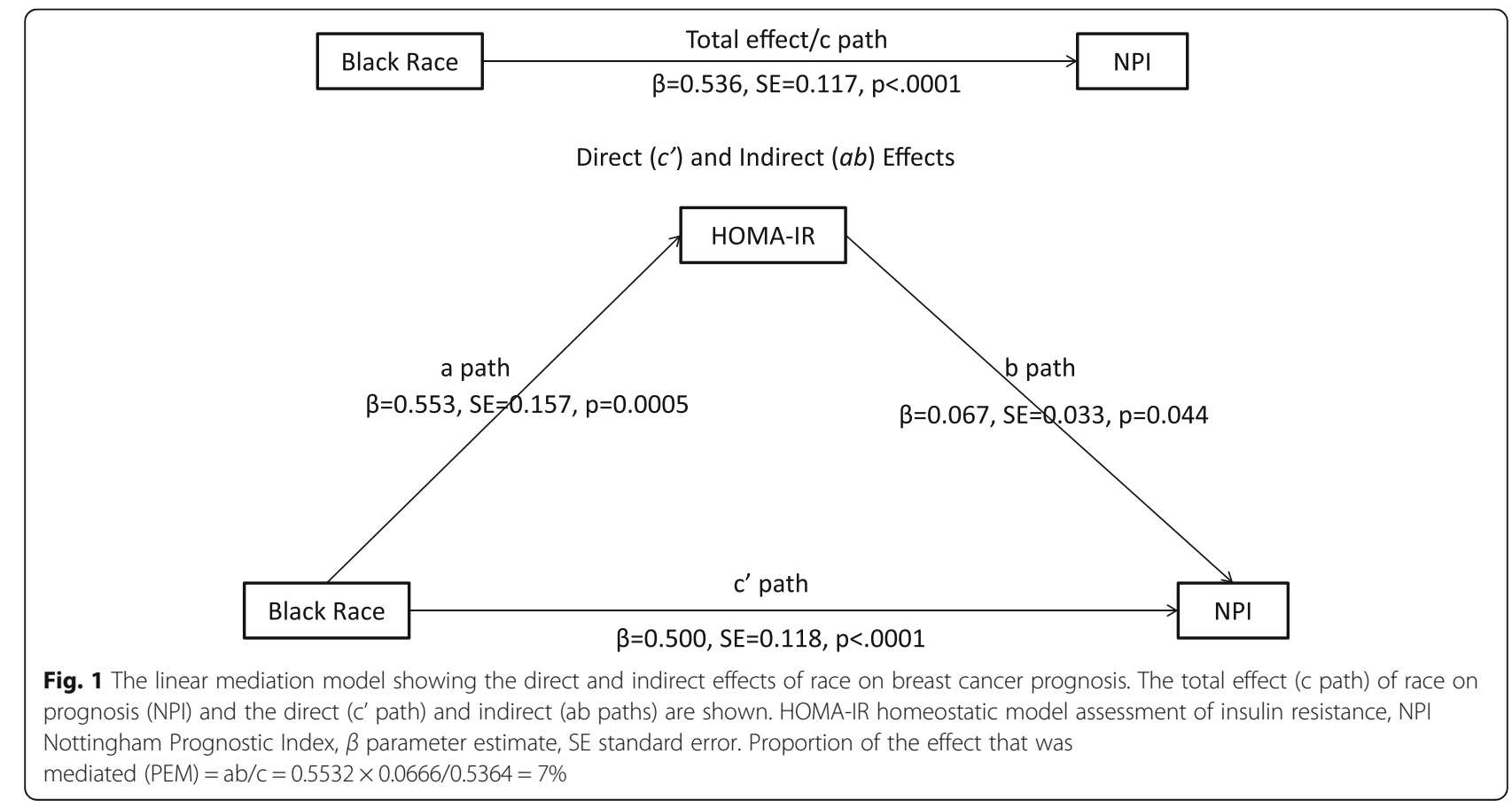




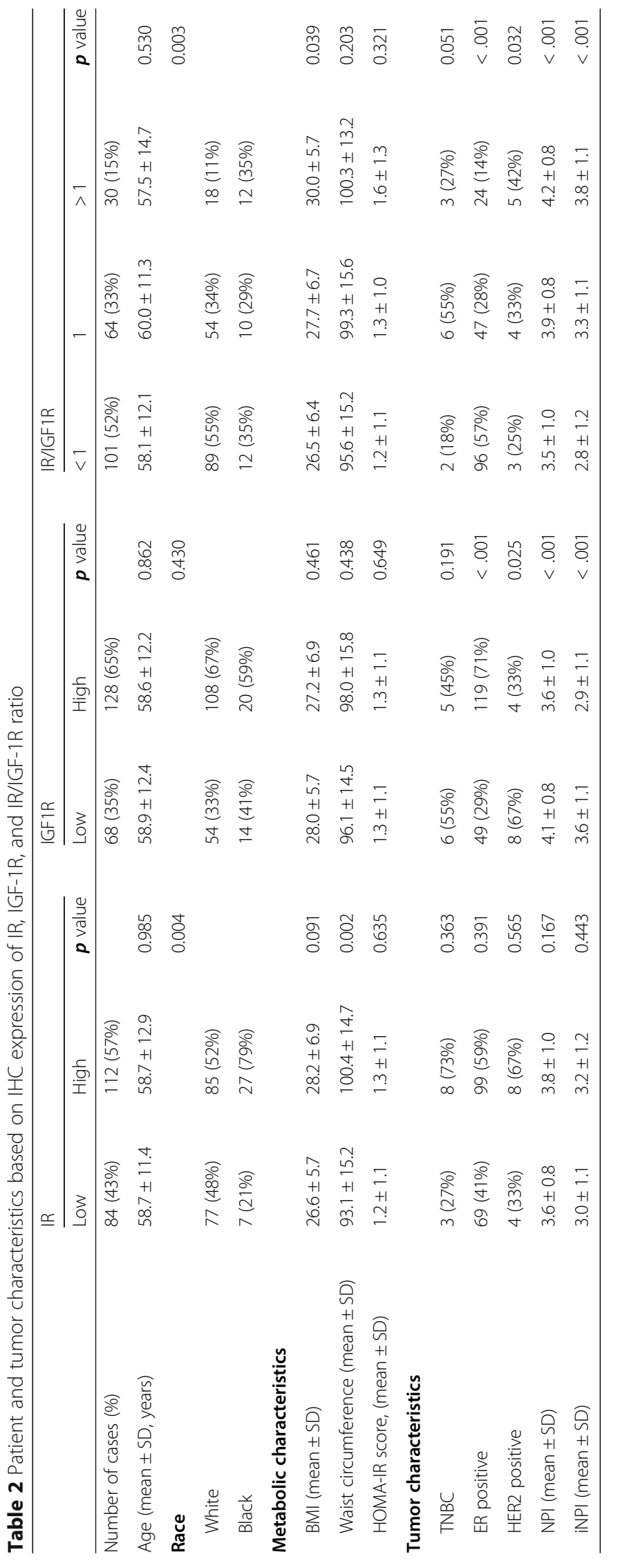



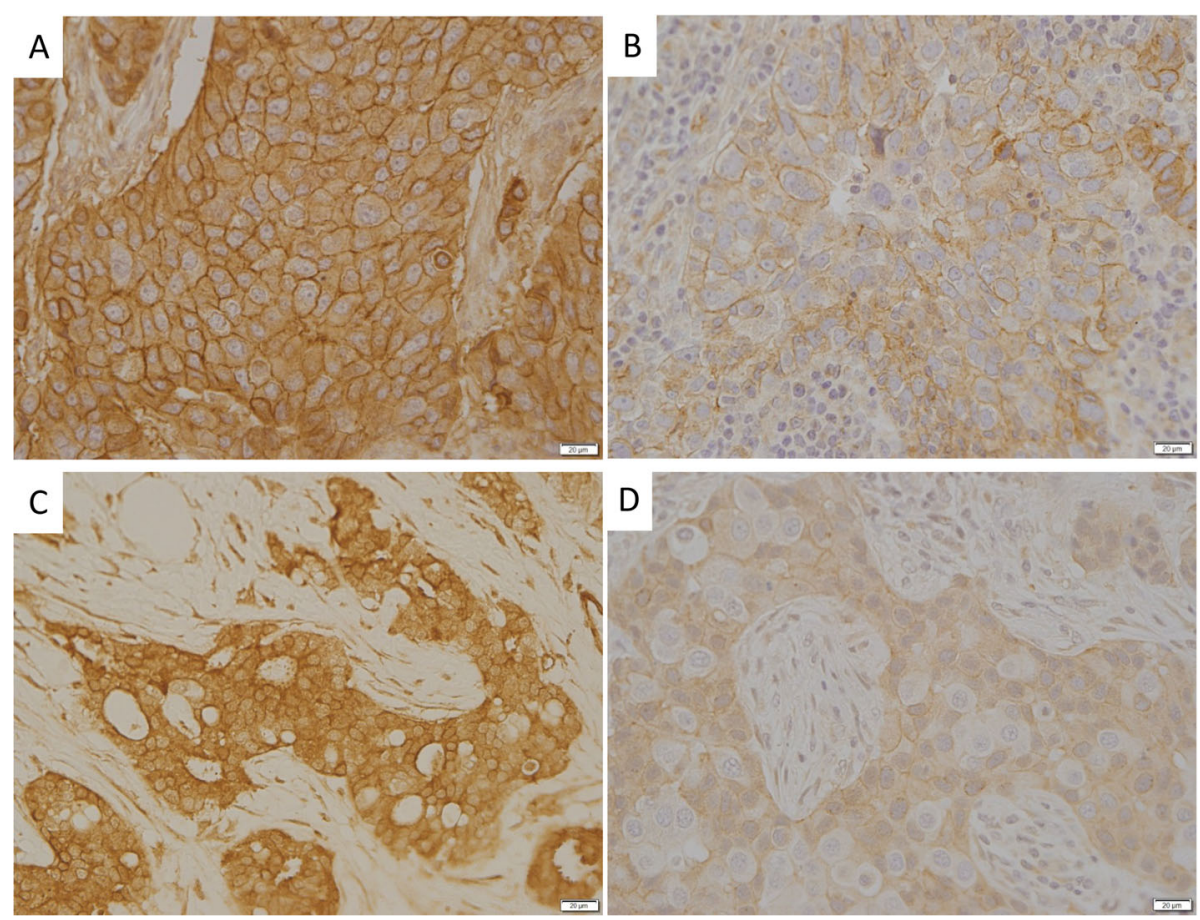

Fig. 2 Representative images of high and low IGF-1R and IR expression by IHC. a High IGF-1R expression. b Low IGF-1R expression. c High IR expression. $\mathbf{d}$ Low IR expression

iNPI (3.8), those with similar levels of expression IR and IGF-1R (ratio =1) had NPI 3.9 and iNPI 3.3, and those with an IR/IGF-1R ratio $<1$ had the lowest NPI (3.5) and iNPI (2.8) scores, $p<0.0001$ for both NPI and iNPI comparisons.

\section{Discussion}

This is the first study to examine in detail the role of insulin resistance in the disparities in breast cancer prognosis between Black women and White women. Herein, we found that insulin resistance was more prevalent in Black women with invasive breast cancer than White women, and insulin resistance mediated in part the link between race and breast cancer prognosis (determined by NPI). Additionally, we found that breast cancers from Black women had higher IR expression and were more likely to have an elevated IR/IGF-1R ratio than tumors from White women. These findings may indicate that Black women are not only more likely to have hyperinsulinemia, but are also more susceptible to the tumor promoting effects of elevated insulin by direct effects of insulin on tumor IR signaling.

We found no differences in breast cancer screening rates or in the AJCC stage at presentation between Black women and White women. Types of insurance were also similar between the two groups. However, despite these similarities, prognosis as quantified by the NPI score was worse in Black women, compared with White women. These data suggest that access to healthcare was not a major contributing factor to the differences in breast cancer prognosis in our study.

A number of lifestyle differences were noted. Black women had lower rates of smoking, alcohol consumption, exercise, and self-described healthy eating habits than White women. Significant differences in education and annual income were observed between the two groups, and Black women had more comorbidities than White women. Diet and exercise are considered to be modifiable risk factors for a number of metabolic diseases, and diet-induced weight loss has been found to improve insulin sensitivity similarly in Black and White women [35]. The differences in insulin resistance may also be related to differences in insulin metabolism between races. Previous studies have found that African American women have higher circulating insulin levels than European American women, due to reduced hepatic insulin clearance $[17,36]$. Similar results have been reported in children [37]. Furthermore, some studies have reported that African American women have earlier menopause than White women, which may also contribute to a higher prevalence of metabolic syndrome in Black women [38, 39]. Based on these previous studies, and the results of our current study, it is possible that the Black women may have long-term exposure to high circulating insulin levels. These high insulin levels 
may contribute to the development of breast cancer subtypes that carry a poor prognosis.

Our examination of IR and IGF-1R by IHC found that high IGF-1R expression was found in ER-positive tumors and those with better prognosis by NPI. These findings are consistent with studies examining IGF1R expression at an RNA level and survival in the Molecular Taxonomy of Breast Cancer International Consortium (METABRIC) and The Cancer Genome Atlas (TCGA) datasets [31, 32]. Similarly, high IGF-1R expression by IHC has previously been associated with ER positivity in breast cancer [33, 40-43]. We found no association between IR expression and ER or HER2 status, which is also similar to previous findings [33]. Some previous studies have reported decreased survival in women with high tumor IR expression [44, 45], although not all studies have reported this association [33]. In our current study, we found no association between IR expression and prognosis; however, we did find having higher IR/ IGF-1R ratio was associated with a worse prognosis. Preclinical studies have reported that higher IR/IGF-1R ratio may be indicative of cells that are more sensitive to the growth promoting effects of insulin, and resistance to therapies $[34,46]$. In our current study, we found that more Black women had tumors with high IR expression and high IR/IGF-1R ratio. In the context of previously published studies, these results suggest that Black women may be more susceptible to the cancer promoting effects of hyperinsulinemia, due to higher levels of circulating insulin and higher ratio of tumor IR/IGF-1R expression.

Limitations include the cross-sectional design, which meant we were unable to determine the duration of insulin resistance prior to breast cancer diagnosis and led us to determine prognosis through the NPI. However, the NPI has previously been well-validated as a prognostic indicator in different populations [47]. Additionally, it predicts prognosis independent of any future differences in breast cancer treatments that may contribute to disparities in breast cancer survival. We also had incomplete data on some breast cancer risk factors, including reproductive history and parity. The prevalence of obesity as defined by BMI in our study was lower than anticipated for a US population. Recent US population studies report that $35.5 \%$ of White women and $56.9 \%$ of Black women ages 20 years and over are obese [48]. The lower prevalence of obesity in our study is likely related to the geographical regions in which this study was performed. The prevalence of self-reported obesity by BMI among US adults in New York, New Jersey, and Connecticut are between 25 and 30\% [49]. Our relatively low prevalence of obesity is also likely to explain the lower than anticipated HOMA-IR results. The NHANES III reported that $25 \%$ of US adults without diabetes have HOMA-IR scores $>2.8$ [21]. In our population, only $11 \%$ of White women and $17 \%$ of Black women had HOMA-IR scores of $>2.8$. While the focus of our study was to examine the link between insulin resistance and disparities in prognosis in women with newly diagnosed breast cancer, we acknowledge that this is certainly just one of a number of complex factors that contribute to racial disparities in breast cancer prognosis.

\section{Conclusions}

Overall, our study finds that insulin resistance is one factor that contributes to the worse prognosis in breast cancer between Black and White women, potentially through direct effects of insulin on the tumor IR. Given the differences in circulating insulin levels and tumor IR expression between Black women and White women, it will be important in future studies to explore whether lowering insulin levels or targeting IR signaling will improve breast cancer survival disparities.

\section{Supplementary information}

Supplementary information accompanies this paper at https://doi.org/10. 1186/s13058-020-01281-y.

Additional file 1. Supplementary Methods.

\section{Abbreviations}

ER: Estrogen receptor; HER2: Human epidermal growth factor receptor 2; HOMA-IR: Homeostatic model assessment of insulin resistance; IGF-

1R: Insulin-like growth factor receptor; IR: Insulin receptor; MetS: Metabolic syndrome; NPI: Nottingham Prognostic Index; PR: Progesterone receptor;

TNBC: Triple-negative breast cancer

\section{Acknowledgements}

The authors would like to thank Shabnam Jaffer for her contributions to this research.

\section{Authors' contributions}

EJG, NA, and DLR conceived and designed the study plan. KF collated and cleaned the data and performed the statistical analysis. SF, EP, NF, SB, BK, MP, $\mathrm{LC}, \mathrm{TK}, \mathrm{RF}, \mathrm{DC}$, and NA recruited patients, labs, pathology specimens, and reports. AN, IM, and EJG were involved in IHC specimen collection, storage, $I H C$ protocol optimization, imaging, and analysis of slides. EJG, KF, NA, and DLR reviewed and analyzed the data and drafted the manuscript. All authors read and edited the manuscript and approved its submission.

\section{Funding}

This work was supported by the National Cancer Institute at the National Institutes of Health (R01CA171558 to N.B and DLR; R01CA128799 to DLR; K08CA190770 to E.J.G).

\section{Availability of data and materials}

The data that support the findings in this study are not publically available; however, data are available from the authors upon reasonable request and with permission of the participating sites' institutional review boards.

\section{Ethics approval and consent to participate}

Institutional Review Board approval was obtained at all participating sites, and patients consented to participate. All data were collected in adherence with the IRB protocols.

Consent for publication

All patients consented to participate in this study. 


\section{Competing interests}

SMF, NBF, SKB, LC, KF, AN, TK, RF, IMA, and DC report no potential conflicts of interest. EJG: advisory board for Novartis; DLR: advisory board for AstraZeneca and Mankind and consultant for Janssen; EP: stock ownership in Remedy Pharmaceuticals, Angiocrine, Viewpoint, TMRW; BK: advisory board for and honoraria from Genentech; NAB: research funding from Pfizer.

\section{Author details}

'Division of Endocrinology, Diabetes and Bone Disease, Icahn School of Medicine at Mount Sinai, 1428 Madison Avenue, Box 1055, New York, NY 10029, USA. ${ }^{2}$ Department of Medicine, Icahn School of Medicine at Mount Sinai, New York, NY, USA. ${ }^{3}$ Tisch Cancer Institute at Mount Sinai, Icahn School of Medicine at Mount Sinai, New York, NY, USA. ${ }^{4}$ Department of Population Health Science and Policy, Center for Health Equity \& Community Engaged Research, Icahn School of Medicine at Mount Sinai, New York, NY 10029, USA. ${ }^{5}$ Center for Health Equity \& Community Engaged Research, Icahn School of Medicine at Mount Sinai, New York, USA. ${ }^{6}$ Department of Surgery, Columbia University Medical Center, New York, NY, USA. 'Department of Surgery, Icahn School of Medicine at Mount Sinai, New York, NY, USA. ${ }^{8}$ Department of Surgery, Mercy Medical Center, Baltimore, MD, USA. ${ }^{9}$ Department of Surgery, Mount Sinai Beth Israel, New York, NY, USA. ${ }^{10}$ Department of Surgery, Yale School of Medicine, New Haven, CT, USA. ${ }^{11}$ Department of Surgery, Memorial Sloan Kettering Cancer Center, New York, NY, USA. ${ }^{12}$ Department of Surgery, Wayne State University School of Medicine, Detroit, MI, USA. ${ }^{13}$ Department of Pathology and Laboratory Medicine, Hospital of the University of Pennsylvania, Philadelphia, PA, USA.

\section{Received: 27 January 2020 Accepted: 17 April 2020}

\section{Published online: 12 May 2020}

\section{References}

1. Grundy SM. Metabolic syndrome: connecting and reconciling cardiovascular and diabetes worlds. J Am Coll Cardiol. 2006;47(6):1093-100.

2. O'Neill S, O'Driscoll L. Metabolic syndrome: a closer look at the growing epidemic and its associated pathologies. Obesity Reviews. 2015;16(1):1-12.

3. Kabat GC, Kim MY, Lee JS, Ho GY, Going SB, Beebe-Dimmer J, et al. Metabolic obesity phenotypes and risk of breast cancer in postmenopausal women. Cancer Epidemiol Biomarkers Prevention. 2017;26(12):1730-5.

4. Dibaba DT, Ogunsina K, Braithwaite D, Akinyemiju T. Metabolic syndrome and risk of breast cancer mortality by menopause, obesity, and subtype. Breast Cancer Res Treat. 2019;174(1):209-18.

5. Moore JX, Chaudhary N, Akinyemiju T. Metabolic syndrome prevalence by race/ethnicity and sex in the United States, National Health and Nutrition Examination Survey, 1988-2012. Prev Chronic Dis. 2017;14:E24

6. DeSantis CE, Ma J, Goding Sauer A, Newman LA, Jemal A. Breast cancer statistics, 2017, racial disparity in mortality by state. CA Cancer J Clin. 2017;67(6):439-48.

7. Barone BB, Yeh HC, Snyder CF, Peairs KS, Stein KB, Derr RL, et al. Long-term all-cause mortality in cancer patients with preexisting diabetes mellitus: a systematic review and meta-analysis. Jama. 2008;300(23):2754-64.

8. Calle EE, Rodriguez C, Walker-Thurmond K, Thun MJ. Overweight, obesity, and mortality from cancer in a prospectively studied cohort of U.S. adults. N Engl J Med. 2003;348(17):1625-38.

9. Goodwin PJ, Ennis M, Pritchard Kl, Trudeau ME, Koo J, Madarnas Y, et al. Fasting insulin and outcome in early-stage breast cancer: results of a prospective cohort study. J Clin Oncol. 2002;20(1):42-51.

10. Pasanisi P, Berrino F, De Petris M, Venturelli E, Mastroianni A, Panico S. Metabolic syndrome as a prognostic factor for breast cancer recurrences. Int J Cancer. 2006;119(1):236-8.

11. Rauscher GH, Silva A, Pauls H, Frasor J, Bonini MG, Hoskins K. Racial disparity in survival from estrogen and progesterone receptor-positive breast cancer: implications for reducing breast cancer mortality disparities. Breast Cancer Res Treat. 2017;163(2):321-30.

12. Daly B, Olopade Ol. A perfect storm: how tumor biology, genomics, and health care delivery patterns collide to create a racial survival disparity in breast cancer and proposed interventions for change. CA Cancer J Clin. 2015;65(3):221-38.

13. Newman LA. Breast cancer disparities: socioeconomic factors versus biology. Ann Surg Oncol. 2017;24(10):2869-75.

14. Gallagher EJ, LeRoith D, Karnieli E. The metabolic syndrome--from insulin resistance to obesity and diabetes. Endocrinol Metab Clin N Am. 2008;37(3): 559-79 vii.
15. Ferguson RD, Novosyadlyy R, Fierz Y, Alikhani N, Sun H, Yakar S, et al. Hyperinsulinemia enhances c-Myc-mediated mammary tumor development and advances metastatic progression to the lung in a mouse model of type 2 diabetes. Breast Cancer Res. 2012;14(1):R8.

16. Novosyadlyy R, Lann DE, Vijayakumar A, Rowzee A, Lazzarino DA, Fierz Y, et al. Insulin-mediated acceleration of breast cancer development and progression in a nonobese model of type 2 diabetes. Cancer Res. 2010; 70(2):741-51.

17. Piccinini F, Polidori DC, Gower BA, Bergman RN. Hepatic but not extrahepatic insulin clearance is lower in African American than in European American women. Diabetes. 2017:66(10):2564-70.

18. Charlson M, Szatrowski TP, Peterson J, Gold J. Validation of a combined comorbidity index. J Clin Epidemiol. 1994;47(11):1245-51.

19. Survey CfDCaPNHaNE. Anthropometry Procedures Manual 2017. p. 3-20.

20. Alberti KG, Eckel RH, Grundy SM, Zimmet PZ, Cleeman Jl, Donato KA, et al, Harmonizing the metabolic syndrome: a joint interim statement of the International Diabetes Federation Task Force on Epidemiology and Prevention; National Heart, Lung, and Blood Institute; American Heart Association; World Heart Federation; International Atherosclerosis Society; and International Association for the Study of Obesity. Circulation. 2009; 120(16):1640-5.

21. Ausk KJ, Boyko EJ, loannou GN. Insulin resistance predicts mortality in nondiabetic individuals in the U.S. Diabetes Care. 2010:33(6):1179-85.

22. Galea MH, Blamey RW, Elston CE, Ellis 1O. The Nottingham Prognostic Index in primary breast cancer. Breast Cancer Res Treat. 1992;22(3):207-19.

23. Van Belle V, Van Calster B, Brouckaert O, Vanden Bempt I, Pintens S, Harvey $V$, et al. Qualitative assessment of the progesterone receptor and HER2 improves the Nottingham Prognostic Index up to 5 years after breast cancer diagnosis. J Clin Oncol. 2010;28(27):4129-34.

24. Edge SB, Compton CC. The American Joint Committee on Cancer: the 7th edition of the AJCC cancer staging manual and the future of TNM. Ann Surg Oncol. 2010;17(6):1471-4.

25. Balslev I, Axelsson CK, Zedeler K, Rasmussen BB, Carstensen B, Mouridsen HT. The Nottingham Prognostic Index applied to 9,149 patients from the studies of the Danish Breast Cancer Cooperative Group (DBCG). Breast Cancer Res Treat. 1994;32(3):281-90.

26. Parisi F, Gonzalez AM, Nadler Y, Camp RL, Rimm DL, Kluger HM, et al. Benefits of biomarker selection and clinico-pathological covariate inclusion in breast cancer prognostic models. Breast cancer research : BCR. 2010;12(5):R66.

27. McShane LM, Altman DG, Sauerbrei W, Taube SE, Gion M, Clark GM, et al. Reporting recommendations for tumor marker prognostic studies. J Clin Oncol. 2005;23(36):9067-72.

28. Wolff AC, Hammond ME, Hicks DG, Dowsett M, McShane LM, Allison KH, et al. Recommendations for human epidermal growth factor receptor 2 testing in breast cancer: American Society of Clinical Oncology/College of American Pathologists clinical practice guideline update. J Clin Oncol. 2013; 31(31):3997-4013.

29. Henriksen KL, Rasmussen BB, Lykkesfeldt AE, Moller S, Ejlertsen B, Mouridsen HT. Semi-quantitative scoring of potentially predictive markers for endocrine treatment of breast cancer: a comparison between whole sections and tissue microarrays. J Clin Pathol. 2007;60(4):397-404.

30. Allred DC, Harvey JM, Berardo M, Clark GM. Prognostic and predictive factors in breast cancer by immunohistochemical analysis. Modern Pathol. 1998;11(2):155-68.

31. Farabaugh SM, Boone DN, Lee AV. Role of IGF1R in breast cancer subtypes, stemness, and lineage differentiation. Front Endocrinol. 2015:6:59.

32. Obr AE, Kumar S, Chang YJ, Bulatowicz JJ, Barnes BJ, Birge RB, et al. Insulinlike growth factor receptor signaling in breast tumor epithelium protects cells from endoplasmic reticulum stress and regulates the tumor microenvironment. Breast Cancer Res. 2018;20(1):138.

33. Mulligan AM, O'Malley FP, Ennis M, Fantus IG, Goodwin PJ. Insulin receptor is an independent predictor of a favorable outcome in early stage breast cancer. Breast Cancer Res Treat. 2007;106(1):39-47.

34. Ulanet DB, Ludwig DL, Kahn CR, Hanahan D. Insulin receptor functionally enhances multistage tumor progression and conveys intrinsic resistance to IGF-1R targeted therapy. Proc Natl Acad Sci U S A. 2010;107(24):10791-8.

35. Gower BA, Weinsier RL, Jordan JM, Hunter GR, Desmond R. Effects of weight loss on changes in insulin sensitivity and lipid concentrations in premenopausal African American and white women. Am J Clin Nutr. 2002; 76(5):923-7. 
36. Ellis AC, Alvarez JA, Granger WM, Ovalle F, Gower BA. Ethnic differences in glucose disposal, hepatic insulin sensitivity, and endogenous glucose production among African American and European American women. Metab Clin Exp. 2012;61(5):634-40.

37. Arslanian SA, Saad R, Lewy V, Danadian K, Janosky J. Hyperinsulinemia in African-American children: decreased insulin clearance and increased insulin secretion and its relationship to insulin sensitivity. Diabetes. 2002;51(10): 3014-9.

38. Bromberger JT, Matthews KA, Kuller LH, Wing RR, Meilahn EN, Plantinga P. Prospective study of the determinants of age at menopause. Am J Epidemiol. 1997;145(2):124-33.

39. Gurka MJ, Vishnu A, Santen RJ, DeBoer MD. Progression of metabolic syndrome severity during the menopausal transition. J Am Heart Assoc. 2016;5(8).

40. Bhargava R, Beriwal S, McManus K, Dabbs DJ. Insulin-like growth factor receptor-1 (IGF-1R) expression in normal breast, proliferative breast lesions, and breast carcinoma. Appl Immunohistochem Mol Morphol. 2011;19(3): 218-25.

41. Aaltonen KE, Rosendahl AH, Olsson H, Malmstrom P, Hartman L, Ferno M. Association between insulin-like growth factor-1 receptor (IGF1R) negativity and poor prognosis in a cohort of women with primary breast cancer. BMC Cancer. 2014;14:794

42. Mountzios G, Aivazi D, Kostopoulos I, Kourea HP, Kouvatseas G, Timotheadou E, et al. Differential expression of the insulin-like growth factor receptor among early breast cancer subtypes. PLoS One. 2014;9(3):e91407.

43. Yerushalmi R, Gelmon KA, Leung S, Gao D, Cheang M, Pollak M, et al. Insulin-like growth factor receptor (IGF-1R) in breast cancer subtypes. Breast Cancer Res Treat. 2012;132(1):131-42.

44. Law JH, Habibi G, Hu K, Masoudi H, Wang MY, Stratford AL, et al. Phosphorylated insulin-like growth factor-i/insulin receptor is present in all breast cancer subtypes and is related to poor survival. Cancer Res. 2008; 68(24):10238-46.

45. Mathieu MC, Clark GM, Allred DC, Goldfine ID, Vigneri R. Insulin receptor expression and clinical outcome in node-negative breast cancer. Proc Assoc Am Physicians. 1997;109(6):565-71.

46. Fagan DH, Uselman RR, Sachdev D, Yee D. Acquired resistance to tamoxifen is associated with loss of the type I insulin-like growth factor receptor: implications for breast cancer treatment. Cancer Res. 2012;72(13):3372-80.

47. Rakha EA, Reis-Filho JS, Baehner F, Dabbs DJ, Decker T, Eusebi V, et al. Breast cancer prognostic classification in the molecular era: the role of histological grade. Breast Cancer Research. 2010;12(4):207.

48. Arroyo-Johnson C, Mincey KD. Obesity epidemiology worldwide. Gastroenterol Clin N Am. 2016;45(4):571-9.

49. Petersen R, Pan L, Blanck HM. Racial and ethnic disparities in adult obesity in the United States: CDC's tracking to inform state and local action. Prev Chronic Dis. 2019;16:E46.

\section{Publisher's Note}

Springer Nature remains neutral with regard to jurisdictional claims in published maps and institutional affiliations.

Ready to submit your research? Choose BMC and benefit from:

- fast, convenient online submission

- thorough peer review by experienced researchers in your field

- rapid publication on acceptance

- support for research data, including large and complex data types

- gold Open Access which fosters wider collaboration and increased citations

- maximum visibility for your research: over $100 \mathrm{M}$ website views per year

At BMC, research is always in progress.

Learn more biomedcentral.com/submissions 